\title{
Cutaneous Hormonal Control of Melanocyte DNA Repair through Camp Signaling
}

\section{Stuart G Jarrett and John A D'Orazio*}

Markey Cancer Center and the Departments of Pediatrcs, University of Kentucky College of Medicine, USA

*Corresponding author: John A D'Orazio, M.D., Ph.D., Associate Professor of Pediatrics, University of Kentucky College of Medicine, Markey Cancer Center, Combs Research Building 204, 800 Rose Street, Lexington, KY 40536-0096, USA, Tel: (859) 323-6238; Fax: (859) 257-8940; E-mail: jdorazio@uky.edu

Rec date: Mar 25, 2015; Acc date: Jun 04, 2015; Pub date: Jun 06, 2015

Copyright: @ 2015 Jarrett SG, et al. This is an open-access article distributed under the terms of the Creative Commons Attribution License, which permits unrestricted use, distribution, and reproduction in any medium, provided the original author and source are credited.

\section{Editorial}

Melanoma is roughly 20 times more common in persons with fair complexions compared to those with darker skin tones [1]. Even among lightly-pigmented individuals, melanoma risk varies between people, being highest among those who burn rather than tan upon UV exposure [2]. Many of the same genes that regulate the tanning response also control how well melanocytes cope with UV damage [3]. Since UV is causative for a substantial portion of melanomas, melanoma risk is directly affected by melanocyte UV responses. We and others have been interested in the melanocortin signaling axis because the vigor of melanocortin responses is a major predictor of melanoma risk [4]. Melanocortin signaling is a hormonally active pathway in the skin initiated by two major melanocortins produced by the pituitary-adrenocorticotropic hormone (ACTH) and alphamelanocyte stimulating hormone $(\alpha-\mathrm{MSH})$, both of which are also produced in the epidermis and upregulated after UV exposure [5]. Melanocortins influence melnaocytes through a cell surface Gscoupled receptor known as the melanocortin 1 receptor (MC1R). When bound by agonistic ligands (ACTH or a-MSH), the MC1R activates adenylyl cyclase which in turn generates the second messenger CAMP. cAMP induction upregulates production of melanin which gets deposited throughout the epidermis to block further UV penetration into the skin (the "tanning" response) [6] and also augments DNA repair.

UV radiation has many effects on macromolecules and cells of the skin. Aside from the conversion of 7,8-dehydrocholesterol to previtamin D3, which is necessary for natural cutaneous production of vitamin $\mathrm{D}$, most UV effects are deleterious to cells of the skin. UV promotes structural and chemical changes to proteins, RNA and lipids, however it is primarily through its effects on DNA that impact cancer risk. UV causes covalent changes to nucleotide bases within DNA by the creation of abnormal links between adjacent pyrimidines. If left unrepaired, these "photoproducts" - cyclopyrimidine dimers and $[6,4]$ photoproducts-interfere with gene expression and replication by interfering with RNA and DNA polymerases. Worse, if the cell manages to replicate with photoproducts in place, then permanent "UV signature" mutations result in the daughter cells. These TT-to-CC and CC-to-TT dipyrimidine transitions are very commonly found in melanoma $[7,8]$ therefore UV damage and mutagenesis are clearly linked with melanoma development.

From a public heath standpoint, melanoma incidence has been steadily rising in the US for decades. Whereas roughly 1 in 1,500 Americans was diagnosed with melanoma in the 1930's, today approximately 1 in 50 people (2\% of the population) will develop melanoma at some point in his/her life. Many factors likely explain the increasing prevalence of disease including increased recreational sun exposure, better disease surveillance, an aging population and the proliferation of indoor tanning facilities. Though important therapeutic advances are being made in molecular targeting and immunotherapy against melanoma, the great majority of patients with advanced melanoma still die of their disease. Roughly 10,000 Americans now die of melanoma each year, and melanoma often affects young adults and people in the prime of life [1]. Therefore, there is a great need to understand early events in melanocyte carcinogenesis, particularly with regard to how melanocytes resist UV mutagenesis.

In recent years, we and others have noted that the melanocortin signaling axis controls not only skin pigment responses but also directly regulates melanocyte DNA repair [3,9-13]. When activated and functional, MC1R/cAMP signaling boosts the ability of melanocytes to rid their DNA of UV photoproducts. The mechanisms that mediate MC1R augmentation of melanocytic DNA repair responses have only recently begun to be defined. We recently reported that the critical molecular event linking MC1R signaling to DNA repair is a unique phosphorylation event of the global cell damage response protein "ataxia and rad3-related" (ATR). When cAMP levels are induced either by MSH-MC1R interactions or pharmacologically with adenylyl cyclase activation, cAMP-dependent protein kinase (PKA) becomes activated and phosphorylates ATR on its Serine 435 (S435) residue. This post-translational modification causes ATR to associate with a key DNA repair factor known as xeroderma pigmentosum A protein (XPA) [3]. XPA is one of eight core proteins that make up the nucleotide excision repair (NER) pathway, the genome maintenance pathway charged with the removal of UV photoproducts to prevent UV mutagenesis. We found that XPA and pS435-ATR localize to UV photoproducts in a greatly accelerated and enhanced manner if melanocytes have been stimulated through MC1R signaling or cAMP activation (Figure 1).

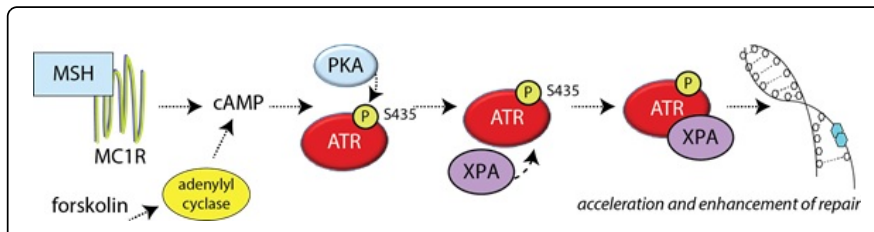

Figure 1: MC1R-mediated repair in melanocytes. cAMP generated from melanocortin signaling or through pharmacologic adenylyl cyclase activation promotes PKA-dependent ATR phosphorylation on S435 which binds to XPA, translocates to nuclear photodamage, and accelerates nucleotide excision repair (NER). 


\begin{abstract}
S435 is part of a PKA target sequence (RRXS*) within ATR's predicted nuclear localization sequence (425DGISPKRRRLSSSLNPSKRAP), suggesting that its phosphorylation might impact ATR's nuclear localization, possibly through interactions with nuclear importins [14]. Indeed, colocalization studies of p-S435 ATR and XPA suggest that PKA modification promotes nuclear entry of ATR-XPA in order to prime NER for DNA damage [3] and PKAdirected nuclear localization of DNA-PK, another PIKK family member, has also been reported [15]. Alternatively, PKA-mediated phosphorylation of ATR at S435 may optimize NER through enhanced intranuclear interactions with XPA to facilitate transport and/or assembly at sites of UV damage. Our findings suggest that PKAmediated phosphorylation of ATR at S435 is an important event that dynamically regulates early recruitment and assembly of XPA and possibly other DNA repair proteins to sites of UV damage in order to optimize NER [3].
\end{abstract}

Melanocortin signaling may also impact genome stability through other mechanisms. MC1R, for example, is a key regulator of signaling mediators of the damage response such as p38, p53, ATR and ATM in response to UV $[10,11]$, and others found that melanocortin-enhanced DNA repair was mediated by increased levels of the DNA damage recognition factor XPC as well as $\mathrm{H} 2 \mathrm{AX}$ [12]. Additionally, MC1R signaling induced the transcription of the NR4A subfamily of nuclear receptors, which were recruited to sites of nuclear DNA damage together with XPC and XPE [16-18]. Thus, melanocortin/cAMP signaling represents a global regulator of melanocytic NER and genome maintenance.

These observations have many translational implications. Firstly, since MC1R signaling directly regulates melanocytic NER, people with inherited loss-of-signaling MC1R polymorphisms (very common among fair-skinned, UV-sensitive and melanoma-prone individuals) accumulate more UV mutations not just because of defective pigment production but also because of blunted NER. NER is exceptionally important for melanoma resistance, as evidenced by the natural history of patients with xeroderma pigmentosum (XP), who, because of defective NER caused by the homozygous loss of one of the core NER proteins (such as XPA), have up to a 2,000-fold increased risk of melanoma [19]. Therefore, we reason that blunted NER from MC1R dysfunction would also affect melanoma risk, albeit not to the extent of complete NER loss. Our data also suggest potential therapeutic implications. It may be possible to restore MC1R signaling in MC1Rdefective individuals through pharmacologic manipulation of the MSH-MC1R signaling axis $[9,20]$ and in so doing afford their melanocytes the many UV-protective benefits that cAMP signaling has to offer. Finally, we recently reported that physiologic MC1R hormonal antagonists agouti signaling protein (ASiP) and beta-defensin 3 (BD3) block and/or down-regulate the melanocortin signaling DNA repair axis [13], raising the possibility that melanocyte NER and subsequent melanoma risk may be controlled in part by the presence of MC1R antagonists, some of which are known to be induced by inflammation and infectious agents [21]. Discovering the molecular events that control these pathways will facilitate the informed development of rational and targeted melanoma-preventive strategies to reduce the risk of melanoma.

\section{References}

1. Eggermont AM, Spatz A, Robert C (2014) Cutaneous melanoma. Lancet 383: $816-827$.
2. Bliss JM, Ford D, Swerdlow AJ, Armstrong BK, Cristofolini M, et al. (1995) Risk of cutaneous melanoma associated with pigmentation characteristics and freckling: systematic overview of 10 case-control studies. The International Melanoma Analysis Group (IMAGE). Int J Cancer 62: 367-376.

3. Jarrett SG, Wolf Horrell EM, Christian PA, Vanover JC, Boulanger MC, et al. (2014) PKA-mediated phosphorylation of ATR promotes recruitment of XPA to UV-induced DNA damage. Mol Cell 54: 999-1011.

4. Kennedy C, ter Huurne J, Berkhout M, Gruis N, Bastiaens M, et al. (2001) Melanocortin 1 receptor (MC1R) gene variants are associated with an increased risk for cutaneous melanoma which is largely independent of skin type and hair color. J Invest Dermatol 117: 294-300.

5. Cui R, Widlund HR, Feige E, Lin JY, Wilensky DL, et al. (2007) Central role of $\mathrm{p} 53$ in the suntan response and pathologic hyperpigmentation. Cell 128: 853-864.

6. Suzuki I, Cone RD, Im S, Nordlund J, Abdel-Malek ZA (1996) Binding of melanotropic hormones to the melanocortin receptor MC1R on human melanocytes stimulates proliferation and melanogenesis. Endocrinology 137: 1627-1633.

7. Hodis E, Watson IR, Kryukov GV, Arold ST, Imielinski M, et al. (2012) A landscape of driver mutations in melanoma. Cell 150: 251-263.

8. Lawrence MS, Stojanov P, Mermel CH, Robinson JT, Garraway LA, et al. (2014) Discovery and saturation analysis of cancer genes across 21 tumour types. Nature 505: 495-501.

9. Abdel-Malek ZA, Ruwe A, Kavanagh-Starner R, Kadekaro AL, Swope V, et al. (2009) alpha-MSH tripeptide analogs activate the melanocortin 1 receptor and reduce UV-induced DNA damage in human melanocytes. Pigment Cell Melanoma Res 22: 635-644.

10. Kadekaro AL, Chen J, Yang J, Chen S, Jameson J, et al. (2012) Alphamelanocyte-stimulating hormone suppresses oxidative stress through a p53-mediated signaling pathway in human melanocytes. Mol Cancer Res 10: 778-786

11. Wong SS, Ainger SA, Leonard JH, Sturm RA (2012) MC1R variant allele effects on UVR-induced phosphorylation of p38, p53, and DDB2 repair protein responses in melanocytic cells in culture. J Invest Dermatol 132: 1452-1461.

12. Swope V, Alexander C, Starner R, Schwemberger S, Babcock G, et al. (2014) Significance of the melanocortin 1 receptor in the DNA damage response of human melanocytes to ultraviolet radiation. Pigment Cell Melanoma Res 27: 601-610.

13. Jarrett SG, Wolf Horrell EM, Boulanger MC, D'Orazio JA (2015) Defining the Contribution of MC1R Physiological Ligands to ATR Phosphorylation at Ser435, a Predictor of DNA Repair in Melanocytes. J Invest Dermatol .

14. Li Z, Musich PR, Cartwright BM, Wang H, Zou Y (2013) UV-induced nuclear import of XPA is mediated by importin- $\alpha 4$ in an ATR-dependent manner. PLoS One 8: e68297.

15. Huston E, Lynch MJ, Mohamed A, Collins DM, Hill EV, et al. (2008) EPAC and PKA allow CAMP dual control over DNA-PK nuclear translocation. Proc Natl Acad Sci U S A 105: 12791-12796.

16. Smith AG, Luk N, Newton RA, Roberts DW, Sturm RA, et al. (2008) Melanocortin-1 receptor signaling markedly induces the expression of the NR4A nuclear receptor subgroup in melanocytic cells. J Biol Chem 283: 12564-12570.

17. Jagirdar K, Yin K, Harrison M, Lim W, Muscat GE, et al. (2013) The NR4A2 nuclear receptor is recruited to novel nuclear foci in response to UV irradiation and participates in nucleotide excision repair. PLoS One 8: e78075.

18. Yin K, Sturm RA, Smith AG (2014) MC1R and NR4A receptors in cellular stress and DNA repair: implications for UVR protection. Exp Dermatol 23: 449-452.

19. DiGiovanna JJ, Kraemer KH (2012) Shining a light on xeroderma pigmentosum. J Invest Dermatol 132: 785-796.

20. D'Orazio JA, Nobuhisa T, Cui R, Arya M, Spry M, et al. (2006) Topical drug rescue strategy and skin protection based on the role of Mclr in UVinduced tanning. Nature 443: 340-344. 
Citation: Jarrett SG, D'Orazi JA (2015) Cutaneous Hormonal Control of Melanocyte DNA Repair through Camp Signaling . J Carcinogene Mutagene 6: e116. doi:104172/2157-2518.1000e116

Page 3 of 3

21. Wang CQ, Akalu YT, Suarez-Farinas M, Gonzalez J, Mitsui H, et al. (2013) IL-17 and TNF Synergistically Modulate Cytokine Expression while
Suppressing Melanogenesis: Potential Relevance to Psoriasis. J Invest Dermatol 133: 2741-2752. 